RAE-IC, Revista de la Asociación Española de Investigación de la Comunicación vol. 8, núm. 15 (2021), 408-428 ISSN 2341-2690

Recibido el 12 de octubre de 2020 DOI: https://doi.org/10.24137/raeic.8.15.18 Aceptado el 24 de noviembre de 2020

\title{
La construcción de destinatarios en los discursos de Rafael Correa tras su mandato en 2018
}

The construction of recipients in the speeches of Rafael Correa after his mandate in 2018

\author{
Andino Veloz, Byron \\ Universidad Nacional de La Plata (UNLP) \\ byronandinov@gmail.com
}

Forma de citar este artículo:

Andino Veloz, B. (2021). La construcción de destinatarios en los discursos de Rafael Correa tras su mandato en 2018. RAE-IC, Revista de la Asociación Española de Investigación de la Comunicación, 8(15), 408-428. https://doi.org/10.24137/raeic.8.15.18

\section{Resumen:}

Analizamos la estrategia discursiva de Rafael Correa para la construcción de sus prodestinatarios y contradestinatarios con sus representaciones en la política durante 2018, cuando ya no es presidente de la República de Ecuador y es atacado sistemáticamente por el gobierno de Lenín Moreno. Correa desarrolla la lógica de confrontación y antagonismo contra Moreno como centro de sus críticas, a quien lo ata como aliado de medios de comunicación, grupos económicos y políticos. Su relato sobre el pasado y el presente pretende mantener vivo el mito de la Revolución Ciudadana, 
además alerta y crea miedo sobre el peligro para Ecuador por el retorno del "pasado" negativo de inestabilidad y crisis.

Palabras clave: Ecuador, política, discurso político, análisis de discurso, antagonismo

\begin{abstract}
:
We analyze Rafael Correa's discursive strategy for the construction of his pro-recipients and counter-recipients with their political representations in 2018 , when he is out of the presidency of the Republic of Ecuador and is attacked systematically by the government of Lenín Moreno. Correa uses the logic of confrontation and antagonism against Moreno as the center of his criticism, who would be an ally of the media, economic and political groups. His story about the past and the present highlights the myth of the Citizen Revolution, also warns and creates fear about the danger for Ecuador due to the return of the negative "past" of instability and crisis.
\end{abstract}

Keywords: Ecuador, politics, political discourse, discourse analysis, antagonism.

\title{
1. INTRODUCCIÓN
}

El discurso de Rafael Correa ha tenido impacto desde su primera campaña presidencial en 2006, enfatizó un antagonismo que aglutinó en un inicio a movimientos sociales por sus demandas insatisfechas. Fue parte del giro a la izquierda (Stoessel, 2014) que incluyó a gobiernos y movimientos progresistas en Latinoamérica. Además, el exmandatario formó los límites de su nosotros ante sus opositores construidos como los otros, es decir, les puso nombre y desarrolló sobre ellos una narrativa que la mantiene -incluso- más de una década después.

Su relato tiene sustento en una historia política y social compleja para Ecuador en las últimas décadas por inestabilidad institucional (Andrade A., 2006), cambios frecuentes de gobiernos por derrocamientos y destituciones, políticos deslegitimados, corrupción, crisis económica, irregularidades en entidades financieras y mantenimiento de desigualdades sociales. Esa narración la implementó mediante una potente 
comunicación política gubernamental que buscó construir su mito de gobierno como la Revolución Ciudadana (Ávila Nieto, 2012).

El objetivo de este artículo es analizar la renovada construcción de destinatarios como aliados y opositores, nosotros y otros, en los discursos de Rafael Correa en 2018 cuando ya no tiene el control del contexto (Van Dijk, 1999) por estar fuera del gobierno y por los cambios en las articulaciones políticas del país. Correa culminó su mandato en 2017, su sucesor fue su exvicepresidente (entre 2007 y 2013) Lenín Moreno quien ganó las elecciones también por Alianza PAIS, pero que cometió un giro en cuanto a las alianzas políticas con grupos de derecha y élites económicas, modificó su visión sobre políticas públicas y el Estado al llevarlo hacia la lógica de mercado. Moreno colocó a Correa como culpable de la situación del país con el fin de fundamentar ese cambio en su política. Por ello, Correa despliega como respuesta una amplia interdiscursividad.

El exmandatario se apoya en menos agrupaciones debido a sus ataques a movimientos sociales, ambientalistas, sindicales, indígenas, docentes y grupos de izquierda, sus pugnas han seguido con los medios de comunicación (Abad, 2010) y algunos sectores de poder económico. En 2018, el expresidente continúa con esa confrontación, pero tiene incluso menos recursos y estructura política para su nueva incursión como opositor del gobierno de Moreno y de grupos empresariales y económicos.

En este texto analizamos cómo Correa denomina a sus opositores y a sus aliados, luego indagamos qué relata sobre el pasado y el presente de esos mismos prodestinatarios y contradestinatarios en el 2018.

\section{METODOLOGÍA}

Desarrollamos un análisis del discurso político con un enfoque cualitativo que toma en cuenta más el contenido que lo lingüístico. Es una metodología que recoge elementos de una anterior investigación (Andino, 2020) sobre otro político ecuatoriano, pero adaptada para este caso de estudio.

Incluimos los aportes de Eliseo Verón (1987) que consideran los enfrentamientos entre enunciados en una situación comunicativa, con las categorías de destinatarios, 
entidades del imaginario político, componentes y sus subcategorías. En los destinatarios tenemos al nosotros positivo y a los otros negativos:

"El destinatario positivo es esa posición que corresponde a un receptor que participa de las mismas ideas, que adhiere a los mismos valores y persigue los mismos objetivos que el enunciador: el destinatario positivo es antes que todo el partidario. Hablaremos en su caso de prodestinatario (...) El destinatario negativo está por supuesto, excluido del colectivo de identificación: esta exclusión es la definición misma del destinatario negativo. Al destinatario negativo lo llamaremos contradestinatario" (Verón, 1987, p. 17).

Las entidades del imaginario político analizan la relación entre el hablante y el destinatario como conglomerado social. En este punto se indaga a quiénes y cómo nombra Correa como prodestinatarios y contradestinatarios y qué distancia toma con respecto a esas construcciones discursivas.

Las subcategorías de las entidades son los colectivos de identificación que muestran el nosotros inclusivo, son formados por la relación entre el enunciador y el prodestinatario. Para los contradestinatarios, la designación será otra y tendrá sentido negativo. También están las entidades más amplias que los colectivos de identificación y, además, nombraremos los meta-colectivos singulares, los cuales no admiten la cuantificación y son más abarcadores que los colectivos.

Otra categoría es la de componentes, describe cómo el político construye su red de relaciones con las entidades del imaginario. En este texto enfatizamos el componente descriptivo que permite la constatación y hace un balance de una situación mediante lecturas del pasado y del presente, sin embargo, también se toma en cuenta el componente programático que proyecta un futuro.

El corpus analizado incluye 9 discursos de Rafael Correa en 2018. En su mayoría son entrevistas de medios regionales e internacionales como Telesur, Hispan TV, Russia Today y CNN. Por su pérdida de control del contexto (Van Dijk, 1999), el exmandatario tuvo poca presencia en los medios ecuatorianos de alcance nacional, las entrevistas captadas fueron en el público Ecuador TV, además de una entrevista en el medio privado 
Canal 1. También se recogió sus dos discursos en los denominados Enlaces Digitales que transmitía por sus redes sociales y cuentas afines en internet.

\section{ENTIDADES DEL IMAGINARIO POLÍTICO: LA LÓGICA DEL ANTAGONISMO}

\subsection{EL NOSOTROS QUE MANTIENE EL MITO, LA IDEOLOGÍA Y EL PUEBLO}

\subsubsection{La Revolución Ciudadana como gobierno y nuevo movimiento político}

Este metacolectivo sirve para designar su labor en el pasado gobierno y como agrupación política vigente. Correa lo dibuja como un mandato que aplicó un modelo que mejoró la calidad de vida de los ciudadanos, sobre todo de grupos vulnerables, por lo que la Revolución Ciudadana (RC) tenía "la razón" y defendió el interés público (Canal Uno, 2018). Enfatiza el valor de la honestidad en ese nosotros: “¿A qué alto líder de la Revolución Ciudadana se le encontró veinte centavos indebidos en su cuenta?" (Russia Today, 2018), en este caso la interrogación obtiene un valor argumentativo que rechaza la presencia de corrupción.

El uso de la RC fue para impulsar la fundación de una nueva agrupación política para sus prodestinatarios: "en el movimiento Revolución Ciudadana, tenemos un capital político extraordinario, 36\%. Tenemos la convicción, la verdad, los principios, la revolución, no les quepa la menor duda que tenemos el futuro" (Telesur, 2018). En su enumeración construye valores redentores de ese nosotros como la verdad y el futuro, así como su identificación política como revolucionarios con convicción. La RC aparece también con fines electorales, pues a esa fecha se aproximaban los sufragios seccionales de febrero de 2019.

La RC sería una extensión del ethos que proyectaba Correa como alguien desinteresado por el poder y que defiende la "patria nueva" (Russia Today, 2018). Este metacolectivo se extiende más allá de límites territoriales pues existen Comités de la RC en Europa, como en Bélgica (Enlace Digital, 2018) donde reside el exmandatario, entonces refuerza la comunidad imaginada de la patria con sus prodestinatarios en las diásporas. 
Correa construye a la RC también de forma antagónica: "enemigo no es quien está apoyando a la Revolución Ciudadana, enemigo son esos banqueros que ya nos quebraron una vez (...) Que el poder esté en las manos de las grandes mayorías" (Enlace Digital, 2018), enuncia a la RC como sujeto político representante y aglutinador de las grandes mayorías ante su contradestinatario: los banqueros.

\subsubsection{Las izquierdas: pertenencia y diferenciación}

Rafael Correa expuso la concepción ideológica a la que pertenecería:

"Uno no se puede llamar de izquierda si no buscas esa integración porque significa soberanía, dignidad y tener capacidad de lograr esa justicia social, igualdad de oportunidades. Si usted está expuesto a una globalización que le obliga a reducir salarios, impuestos para que venga inversión, para que haya competitividad (y todas las tonterías que siempre se dice), no va a haber justicia social, equidad, ni igualdad de oportunidades" (Russia Today, 2018).

Marca límites sobre qué entiende por la izquierda hoy. Era un momento diferente para los gobiernos del denominado Giro a la Izquierda en la región, el expresidente critica el entreguismo y la derechización de algunos de esos políticos. Es un contexto regional en el que la izquierda dejó de gobernar en varios países:

"El ciclo político no se acorta y así son los procesos históricos: avanzan, tienen pequeños retrocesos, pero nunca vuelven al punto original. Claro, que si son grandes retrocesos como la traición pues ya es un problema diferente. En todo caso, mire, hablando un poco a nivel idealista ya la patria grande no es solo un sueño es una necesidad de supervivencia" (HispanTV, 2018).

Incluye otro metacolectivo más amplio, la patria grande, como interdiscurso de otros mandatarios como Hugo Chávez, Nicolás Maduro y Evo Morales sobre el referente utópico hacia una común pertenencia de las naciones hispanoamericanas, el cual era el mito fundacional de los libertadores, como Simón Bolívar.

Correa indica que la izquierda es perseguida ahora que sus militantes se constituyen como oposición: "empezando por quien le habla, no dicen nada de América Latina 
porque como esto es contra la gente de izquierdas dicen 'bien hechito', como cuando en las dictaduras militares de los 70 se asesinaba comunistas" (CNN, 2018). Él hace alusión a la memoria histórica y compara la situación de la izquierda contemporánea con la de décadas atrás, cree que las nuevas formas de persecución (judicial y mediática) ocurren solo contra la izquierda, sus dirigentes y líderes políticos más visibles (Ecuador TV, 2018).

El expresidente dibuja a la izquierda de la Revolución Ciudadana como diferente a la que existió antes de su llegada al campo político en Ecuador: "Cuando éramos la izquierda del 2\% a 3\% ¿qué lográbamos? Gracias a un liderazgo que no es malo, somos la izquierda que barrió en 14 elecciones" (Ecuador TV, 2018). Correa responde interdiscursivamente a las críticas que hacían a su personalismo político, basándose en resultados electorales para legitimarse, se aleja de la denomina "extrema izquierda" a la que ha colocado como contradestinataria y no como aliada.

\subsubsection{La evocación al pueblo}

Maluf, Cerbino y Ramos (2016) señalan que el pueblo es fuente de autoridad y puede modificar a la misma, los líderes son delegados y ejercen el mandato popular, así lo refería Rafael Correa: "el pueblo ecuatoriano nos benefició, nos reconoció con más de dos terceras partes de la Asamblea" (Ecuador TV, 2018) o "mi pueblo me premió con la máxima autoridad que puede operar un ciudadano que es ser Presidente de la República en tres elecciones seguidas" (Telesur, 2018).

Si se evoca al pueblo (Laclau, 2005) se lo hace como una articulación heterogénea y para ello es necesario constituir o fundar su identidad política. Este proceso de representación se desarrollaría entre el pueblo y el líder como dialógico: la voluntad de un grupo sectorial llega al representante y él demuestra que es compatible con el interés de la comunidad o un todo para gobernarlo.

Correa usó la evocación al pueblo durante su mandato y lo volvió a hacer en 2018 como componente programático para los comicios y para un futuro en el que defienda y 
recupere la "patria nueva". Ese discurso, indica Laclau (2005), es para interceder con otra lógica o causar ruptura en un orden dislocado existente:

"después si quieren una asamblea constituyente, recuperamos la patria (...) hay que votar por un proyecto global, el proyecto de la Revolución Ciudadana para sacar a los banqueros, empresarios corruptos, a los traidores del poder que se nos han robado la patria compañeros" (Enlace Digital, 2018).

El exmandatario asimila a ese sistema dislocado con el gobierno de Lenín Moreno, en el que los grupos de poder recuperaron el manejo de la patria. Ante ello, Correa propone que se debe otorgar nuevamente al pueblo el poder de decisión para salir de ese orden mediante la vía electoral (Cerbino, Maluf y Ramos, 2016).

Correa asumió un rol explicativo y didáctico, en los primeros meses de 2018, en contra de la Consulta Popular propuesta por Moreno. Sin embargo, cree que el pueblo tenía una incapacidad de entendimiento ante la situación política y consideró al pueblo como susceptible de moldeamiento por otros y en un estado pasivo: "Usted está equivocado, primero se puede manipular la opinión del pueblo" (Canal Uno, 2018) o "están engañando al pueblo ecuatoriano" (Telesur, 2018).

Por último, Correa apela insistentemente al pueblo con el pedido de reacción: "por la traición los mismos del pasado han venido, pero no reacciona el pueblo ecuatoriano (...). ¡Pero qué nos pasa, qué nos pasa pueblo ecuatoriano!” (Enlace Digital, 2018). La reacción significaría que el pueblo genere oposición ante el régimen y su coalición política que serían "los mismos del pasado".

\subsection{RENOVACIÓN Y CONTINUIDAD DE LOS CONTRADESTINATARIOS}

\subsubsection{Los traidores que arrebataron Alianza PAIS}

Rafael Correa ha mantenido un discurso antagónico, con una fuerte construcción del nosotros contra ellos, también fuera de la presidencia, así marca los límites dicotómicos que muestran a los otros como diferentes y opositores del pueblo para luchar ante ellos y tratar de establecer una nueva hegemonía (Laclau y Mouffe, 1987). 
Varios de sus excorreligionarios se transformaron en sus contradestinatarios. El que más resalta es Lenín Moreno, quien fue el vicepresidente de Rafael Correa, él dio un giro en su mandato sobre políticas públicas, concepción del Estado y sus aliados políticos, mediante la lógica del consenso (Rancière, 1996) el manejo del poder fue otorgado a grupos que eran contradestinatarios de Correa:

"América Latina debe entender que tenemos un traidor, un impostor profesional de presidente. Hace 9 meses, cuando todavía me necesitaba para campaña, yo 'era el mejor ecuatoriano de todos los tiempos', tú lo escuchabas (...) ahora somos ladrones, jefes de la mafia, hambrientos de poder" (Telesur, 2018).

La nominalización "traidor" es como Correa identificará a Lenín Moreno, lo justifica mediante la argumentación y el relato de hechos pasados que se contraponen con ese presente de la enunciación: “Ahora dice todo lo contrario porque él tuvo el poder y dejó de necesitarnos" (Ecuador TV, 2018). El exmandatario construye a Moreno, mediante adjetivaciones, como un político con valores negativos: "yo he dicho que es una persona sin convicciones (...) no sabíamos que era un traidor, no sabíamos que era desleal" (Canal Uno, 2018), a lo que suma la mentira, inmoralidad, corrupción e hipocresía (Enlace Digital, 2018).

Correa compara a Moreno con Efialtes, un personaje de la mitología griega que traicionó a los espartanos y ayudó a los persas para que puedan derrotarlos en batalla. Es una representación negativa que - al igual que la siguiente metáfora- acude a estereotipos y lugares comunes en el discurso social: "recuerden el pretexto del cuántico porque él estuvo 6 años como vicepresidente y 10 años en Alianza PAIS" (Enlace Digital, 2018). El expresidente lo refiere irónicamente como "cuántico" ya que Moreno hacía alusión a esta disciplina de la física y sus postulados, de esta forma reformula esos enunciados para colocarlos con tono burlón contra Moreno.

El discurso de Correa sobre los "traidores" se extendió a quienes antes lo alababan, pero que en la actualidad lo critican y persiguen, para ello acudió a una fábula: "Esta gente ha actuado como lobo disfrazado de cordero, años adulándonos, diciendo que eran compañeros y esperaron tener poder, después utilizarlo para decir todo lo contrario" 
(Ecuador TV, 2018). Correa estuvo en Alianza PAIS desde su primera campaña en 2006 hasta enero de 2018 cuando se desafilió de la organización, por eso la Revolución Ciudadana sustituyó a ese metacolectivo:

"La Revolución Ciudadana antes era Alianza PAIS, ya no (...) no compañeros nos robaron Alianza PAIS, está en manos de los traidores, voten por quien sea, menos por traidores, menos por PAIS, la vamos a recuperar, estoy seguro que venceremos al final del día, la vamos a recuperar, el movimiento político más grande y más exitoso del país creado con el sudor de nuestra frente" (Enlace Digital, 2018).

Vincula a Alianza PAIS a los nuevos otros construidos como traidores, usurpadores y ladrones. También, el exmandatario se refiere a esos otros como una "dictadura" (Ecuador TV, 2018), farsa, ladrones y embriagados de poder (Telesur, 2018).

\subsubsection{Los viejos partidos y la partidocracia}

Carlos de la Torre (2015) indica que uno de los discursos fuertes de Correa desde el inicio de su mandato fue el ataque a los partidos tradicionales. El motivo fue impulsar en su primera campaña la Asamblea Constituyente de Montecristi, para desprestigiar a esos partidos. Hasta la actualidad, el expresidente los llama la "partidocracia" que designa el poder y la influencia decisoria de esos partidos en la vida política por su monopolio de la actividad pública (Borja, 2018).

En los discursos de 2018 que analizamos se refiere a ellos también como "los viejos políticos" (Telesur, 2018), además de fustigarlos los adhiere al gobierno de Lenín Moreno: “La Alianza PAIS cuántica más la derecha de SUMA, más el roldosismo, más Pachakutik, ese viejo país (...) El pacto con Nebot ya era antes de los diálogos, así nos trata este gobierno, es puro show, pura farsa. El diálogo nacional cuando ya tenían pactos previos repartiéndose el país" (Ecuador TV, 2018), así todos esos otros partidos políticos son considerados contradestinatarios.

\subsubsection{La invalidación de la prensa y desacralización de los medios}

Para Ramos, Maluf y Cerbino (2016), Correa era un receptor privilegiado porque ha tenido capacidad de respuesta pública a los medios. Con la pérdida del control del 
contexto, aprovecha los espacios disponibles mediante entrevistas para mostrarse como ese receptor crítico, en cuanto los límites de esa mediatización se lo permiten.

El exmandatario confronta a las empresas mediáticas como agentes de construcción y reproducción de discursos y representaciones, las cuestiona en el plano ético y las invalida políticamente como agentes de información: “los medios no vienen de Dios, los medios son empresas capitalistas con fines de lucro manejados - como usted ha reconocido en pantalla - por el gran capital internacional y pueden y tienen graves, graves problemas y eso no es solo nuestro derecho, es nuestro deber denunciarlo" (CNN, 2018). Correa desacraliza y trata de desnaturalizar a los medios para mostrar de quiénes son propiedad, su relación con el sistema económico capitalista y la conexión medios-status quo como generalización:

- "Hay periodistas muchas veces muy dudosos que abusan de su poder, persiguen al político honesto porque son los guardianes del status quo. Mire, la prensa es un poder (...). En democracia todo poder debe tener un contrapoder, ¿cuál es el contrapoder de la prensa? Y nuestras democracias han perdido su esencia, que es la voluntad del pueblo, es la voluntad del medio ahora (...) no tenemos Estado de derecho, tenemos Estado de opinión" (Enlace Digital, 2018).

- "Con dolor le tengo que decir: unos graves problemas sobre América Latina se llama prensa, no quiero generalizar, pero esa prensa corrupta que se ha vuelto el nuevo opio de nuestros pueblos" (CNN, 2018).

Usa la interrogación para resaltar lo central de su argumento: la prensa no tiene contrapoder, por lo que Correa asume ese rol para denunciar a la prensa, evidenciar su accionar en la democracia y no someterse a ella (Ecuador TV, 2018). Además hace alusión a Karl Marx y su aforismo "la religión es el opio de los pueblos" para reformularla como figura retórica y utilizarla contra el poder mediático. Explica que la adjetivación "corrupta" es por esconder la verdad, distorsionarla y crear una realidad inexistente (HispanTV, 2018). Correa niega que haya equilibrio, imparcialidad e independencia en los contenidos de la prensa: 
"La complicidad de la prensa corrupta que ha sido el principal partido de oposición de los líderes progresistas y los gobiernos progresistas (...) la sagacidad de cooptar el poder judicial, fiscales jueces como en Brasil, como parcialmente en Ecuador y con la presión de la prensa esos jueces penales pues enseguida hacen lo que la prensa indica" (Ecuador TV, 2018).

Además de las adjetivaciones mencionadas, junta a la prensa con los jueces como cómplices de los ataques en contra de su nosotros político, con lo que forma su ethos de víctima de persecución.

\subsubsection{El ataque a los poderes económicos y financieros}

Antes, Correa tildaba de "pelucón" o "aniñado" a quienes poseen altos recursos económicos, sin embargo en los análisis de 2018 no se encontraron mayores referencias a ese tipo de discurso. Coloca a los grupos de poder económico como antagonistas en el plano político, por ejemplo, en su frase "el viejo país" no solo estaba incluida la "partidocracia", también en el contexto del relato se hablaba de conglomerados económicos que apoyan a Lenín Moreno:

"La gente que lo rodea es por odio a Correa, representantes del viejo país que perdieron sus prebendas. El rato que no les sea útil Lenín Moreno le dan una patada como acostumbran hacer con todos los presidentes al que le daban apoyo coyuntural y buscarán algún otro que sirva a sus intereses" (Telesur, 2018).

Sobre estos grupos de poder, Correa no les colocó sobrenombres o metáforas polémicas recurrentes, pero sí indica que estos grupos, como la Cámara de la Producción y los países hegemónicos, gobiernan ahora Ecuador (HispanTV, 2018).

Las alusiones del expresidente son frecuentes sobre el grupo financiero de los banqueros, como entidad amplia que los engloba como generalidad. Este discurso tuvo presencia sobre todo cuando Correa se dirigía a los ecuatorianos migrantes en sus transmisiones digitales, pues muchos de ellos fueron al extranjero a partir de la crisis financiera de 1999: 
- "Que esta experiencia nos sirva - como canta Silvio- saber asumir al enemigo (...) enemigo es ese banquero que ya nos quebraron una vez, muchos de ustedes están aquí por esos banqueros corruptos, de nuevo en el poder con total impunidad" (Enlace Digital, 2018).

- "Se imagina (...) un Superintendente de bancos, de nuevo un banquero para que nos lleve a la crisis del 99, ¿se imagina todo eso? El reparto de la Patria como botín entre piratas" (Canal Uno, 2018)

Es una referencia del nosotros vs. ellos construida a través de la memoria colectiva ante ese otro forjado socialmente. Aparece una metáfora polémica al asimilar a los banqueros como saqueadores y ladrones conocidos desde una perspectiva histórica, también se los adjetiva como corruptos, mediocres o ambiciosos (Telesur, 2018).

\section{COMPONENTES: EL RETORNO DEL PASADO Y UN PRESENTE DE PERSECUCIÓN}

\subsection{EL ÉNFASIS EN EL MIEDO SOBRE EL PASADO}

Un eje del discurso de Correa es la división del tiempo: el "pasado" sería una etapa distinta a su gobierno (2007-2017). Lo construye de forma antagónica y diferencial con una función pedagógica de explicación y valoración de la historia:

"Había corrupción por el almacenamiento de gas, había corrupción en el no hacer una hidroeléctrica para proteger, la renegociación de las deudas, el no defender al Estado. Yo cuando llegué ya eran 7 u 8 años de la crisis bancaria y todavía no se incautaban las empresas de los Isaías (...). Fueron un tanto más corruptos que Abdalá Bucaram, pusieron a Fabián Alarcón de presidente interino cuando eso no existía, le correspondía a Rosalía Arteaga, hicieron una consulta inconstitucional después una Asamblea Constituyente para clavarnos el neoliberalismo, se repartieron el país, nos llevaron a la crisis" (Ecuador TV, 2018).

Es un pasado narrado con antivalores democráticos. Incluye frecuentemente la apelación a la memoria colectiva y a generar un estado de miedo social que se contagie para evitar repetir crisis políticas, sociales y económicas, manifiesta: 
- "Tuvimos en 10 años 7 presidentes, crisis bancarias, 2 millones de ecuatorianos salieron del país por esta inestabilidad política que va a comenzar de nuevo por la trampa que han hecho. Porque viene otro gobierno igual de sabido o más sabido, hace la misma trampa (...). No tenemos Constitución, no tenemos instituciones y el país se va al caos" (Telesur, 2018).

- "Como el país de los 90 (...) ¿Vamos a volver a ese país? (...) Con esto se acaba la democracia entendamos lo grave que es retroceder 20 años" (Canal Uno, 2018).

Correa utiliza la enumeración de esos hechos para relacionarlos con el hoy, advierte como profecía y como profeta de la política sobre los males sociales que pudieran volver a presentarse, incluso como el fin de la democracia.

\subsection{AUTORREPRESENTACIÓN POSITIVA PARA SU GOBIERNO}

El pasado negativo mencionado se diferencia de un pasado positivo que Correa construye sobre su gobierno:

"El modelo económico de la Revolución Ciudadana dio vuelta al mundo. Yo me canso de recibir invitaciones para conferencias en universidades en la Unión Europea para explicar el modelo económico, el éxito ecuatoriano, cómo duplicamos el tamaño de la economía, cómo redujimos pobreza e inequidad" (Ecuador TV, 2018).

Correa sería el representante y líder visible de la Revolución Ciudadana (RC) ante el mundo, su nosotros tendría un ethos de competencia y trabajo (Cerbino, Maluf y Ramos, 2016) al mencionar que fueron "exitosos" a diferencia de regímenes "derrotados".

Los resultados del modelo ejercido por la RC son defendidos y colocados como argumentos de esa autorepresentación positiva y sirven para establecer límites discursivos ante el neoliberalismo, el pasado negativo y el gobierno de Moreno:

"Resulta que el neoliberalismo es lo correcto y no nuestras políticas que sacaron a 2 millones de ecuatorianos de la pobreza, nos convirtieron en el campeón de la igualdad en América Latina. Tuvimos un crecimiento mucho mayor que el promedio latinoamericano, resulta que esa política ha sido la equivocada y el neoliberalismo que nos quebró en los años 90 eso sí ha sido lo acertado" (HispanTV, 2018). 
Como interdiscurso ante la "cirugía mayor" a la corrupción que planteó Lenín Moreno, Correa responde que su mandato tenía el mejor sistema de compras públicas de América Latina (Ecuador TV, 2018). Sin embargo, el exmandatario efectúa una negación polémica, reconoce que existieron casos de corrupción en su gobierno, pero desvirtúa que todo su mandato fue así. Él retoma momentáneamente a Moreno como parte de ese nosotros para atarlo a una responsabilidad compartida:

"Si fuera cierto, él fue cómplice si fue 10 años parte del gobierno, 6 años como vicepresidente, 10 años como parte de Alianza PAIS (...) yo no te digo que no haya habido un caso de corrupción, nos avergüenza, nos indigna, pero no es cierto que ha habido generalizada corrupción.

(...) luego se aclara y nunca sacan la aclaración (...) cada semana se inventaron un escándalo con el eco de la prensa mercantil para hacer creer a la ciudadanía que todo era corrupción y que había empezado en mi gobierno" (Ecuador TV, 2018).

Correa defiende a la Revolución Ciudadana y acusa a la prensa y al gobierno de ser quienes crean representaciones, que carecerían de verdad, para deslegitimarlo.

\subsection{EL MIEDO EN EL PRESENTE, LA PATRIA EN PELIGRO}

Correa acude a la persuasión de sus destinatarios para prevenir o alarmar sobre un presente y un eventual futuro no deseados: "La patria vive momentos críticos" (Ecuador TV, 2018), "nos están destrozando la Patria (...) los momentos que vive el país son extremadamente graves" (Canal Uno, 2018). Es una lectura pesimista sobre el país que recibiría las consecuencias del mandato de Moreno, a quien lo culpa de eliminar los avances para que el "pasado" negativo vuelva en el presente y tenga un "reparto de la patria como botín" (Canal Uno, 2018):

"La barbarie volvió, el abandono, el quemeimportismo y cómo se está desmantelando servicios públicos, hospitales (...) educación, volvimos a las escuelas unidocentes, las peleas en la universidad Estatal de Guayaquil, qué vergüenza Dios mío (...) para que vuelvan a secuestrar nuestra educación, para que cada año empecemos con 2 meses de paro, para que nuestros chicos aprendan a quemar llantas, no prendan historia, 
geografía, matemática. ¿Quién es el responsable? Y todo para repartirse el poder, no le interesa la patria" (Enlace Digital, 2018).

Correa acude a la dicotomización conocida como 'civilización vs. barbarie', siendo su gobierno el que gozaba de esa racionalidad y verdad, mientras que la periferia es irracional y salvaje: peleas, paro, quema de llantas. Con esto tiene relación la afirmación del exmandatario de que la situación que vive Ecuador es "subdesarrollo" (Telesur, 2018), lo "atrasado" que debe superarse y dejar atrás.

Los dos puntos a los que Correa acude es que se desmantelaron los avances en el país y se revivió a los antiguos poderes, manifiesta que el gobierno de Moreno carece de un ethos de competencia, responsabilidad social y patriotismo, por lo que nominaliza el comportamiento de ese régimen como "entreguista":

"Se ha entregado totalmente a grupos de derecha, los poderes económicos, poder mediático (...) han vuelto los poderes, están gobernando los bancos, están gobernando las grandes corporaciones mediáticas, la cámara de la producción, los países hegemónicos, se ha perdido mucha soberanía y dignidad (...) ya sabemos que no tiene límites ni escrúpulos, no son nada, son títeres" (HispanTV, 2018).

Es la continuación de su relato: se están cumpliendo sus profesías del retorno de ese pasado, además que reclama a los medios de comunicación y a la academia por ser entes pasivos ante la situación de "rompimiento" y "alteración" del orden constitucional que viviría el país (Ecuador TV, 2018).

\subsection{EL LAWFARE: RELACIÓN ENTRE MEDIOS, GOBIERNO Y JUSTICIA}

Parte de la estrategia de Rafael Correa ha sido argumentar que es víctima de persecución política a través de lo judicial y con el soporte de la prensa como amplificadora de esos ataques en la opinión pública. Él y quienes integraron su gobierno han sido procesados y sentenciados por casos de corrupción, por lo que didácticamente explica en qué consistiría esa situación:

- "Se llama lawfare, judicialización de la política, la guerra jurídica. Empieza con un linchamiento mediático con la prensa corrupta, magnificando, exacerbando un caso real 
de corrupción (...). Te quitan el apoyo político, cuando vienen ya los jueces (...) buscan razones para sentenciar porque se mueren de miedo, la presión política, la presión social $y$ aniquilan a esa persona" (Ecuador TV, 2018).

- "Sacan de contexto las cosas con la ayuda de la prensa. Se sentencia en los titulares y una judicatura, un sistema judicial presionado por el poder político, por el mediático lo que hace es tan sólo copiar en los tribunales lo que dijeron los titulares de esa prensa. Entonces se trata de una estrategia regional" (HispanTV, 2018).

El propósito de Correa es desmentir los ataques de la prensa y del discurso gubernamental que lo acusan, ya que desea que no se consoliden como verdades en los sentidos de la ciudadanía. El expresidente indica que se trata de un "acoso mediático" (CNN, 2018) en una batalla política-jurídica-mediática:

"El cerco mediático que hemos tenido (...). Dicen que no iban a ser medios gubernamentales sino medios públicos de la ciudadanía y más que nunca son medios gubernamentales que impiden, por ejemplo, visibilizar mi participación en la campaña (...) muchas entrevistas que me han llamado a última hora diciendo que les Ilamaron a amenazar que les quitaban la frecuencia" (Ecuador TV, 2018).

Esto corresponde a la falta de control del contexto mediático, también porque su acceso al discurso público ha sido bloqueado por canales de televisión y radios, sobre todo privados, tras el permanente conflicto que mantiene con ellos. También estaría el gobierno, con sus aliados y asesores, como coordinador de ese plan en su contra para mediáticamente construir una representación negativa de Correa:

"Infame propaganda que ha hecho este gobierno de este señor durante 8 meses en una muestra de gran deslealtad, asesorado por Jaime Durán Barba experto en guerra sucia, cuya recomendación es un escándalo cada semana (como lo hace con Cristina Fernández de Kirchner) y con la complicidad de la prensa mercantil que coge el escándalo y cuando se le aclara no publica nada" (Ecuador TV, 2018).

Trata de globalizar la situación a la región, ese otro construido por Correa (los medios) no está únicamente en Ecuador, sino que tiene conexiones en otros países por ser parte de ese plan de lawfare en distintos contextos. Como contradestinatarios de Correa 
estaban en 2018 los gobiernos de Ecuador (Moreno) y Argentina (Macri), pues habrían profundizado campañas de desprestigio para elevar su imagen pública argumentando la lucha contra las irregularidades: "lo ha rentabilizado el caso Odebrecht, sin él qué sería el gobierno este momento. El discurso anticorrupción, vieron que era rentable políticamente y lo generalizaron y manipularon a la gente" (Ecuador TV, 2018).

El expresidente indica que esos gobiernos se han tomado la institucionalidad de cada país para instrumentalizarla a su favor y destruir políticamente a sus opositores. Además anuncia el componente programático del lawfare en Ecuador: "van a detener el juicio 8-10 años hasta que el delito prescriba y así me matan civilmente, políticamente durante esos años. Es la estrategia" (Russia Today, 2018).

\section{A MODO DE CIERRE}

El discurso de Rafael Correa durante 2018 evidencia su reacción ante la pérdida del contexto comunicativo y político tras dejar la presidencia y ser atacado discursivamente. Aplica una nueva estrategia para su autorrepresentación positiva y una renovada construcción de opositores mediante la lógica del antagonismo.

Uno de los elementos relevantes e invariantes de sus juegos de discurso (Verón, 1987) es la construcción del mito de la Revolución Ciudadana. Es un metacolectivo al cual le atribuye un ethos de competencia y eficacia para construir a su nosotros en el terreno electoral y político. También incluye a sus prodestinatarios en el colectivo de identificación de la izquierda, que a la vez sería su paraguas ideológico, aunque menospreció a otros grupos de esa tendencia en el país.

Correa vuelve a evocar al pueblo como un metacolectivo, al no admitir su cuantificación en el discurso no se explica específicamente quiénes forman parte de él. El exmandatario considera al pueblo como mandante y decidor de la voluntad política, sin embargo lo menciona más con fines electorales coyunturales y le otorga un carácter pasivo como manipulable por lo que apela a su reacción ante la situación de Ecuador durante el mandato de Moreno. 
En esta formación antagónica aparecen los otros en ese nuevo contexto, coloca a Lenín Moreno como eje central y lo cataloga como traidor. Alrededor de Moreno, Correa coloca como contradestinatarios a Alianza PAIS (AP) y como traidores a sus excorreligionarios que se quedaron en el 'Gobierno de todos', su antiguo colectivo de identificación Alianza PAIS ahora es su opositor. Además, indica que los "viejos políticos", medios de comunicación, grupos empresariales, financieros y poderes económicos son aliados cercanos a Moreno, invalida su legitimidad y credibilidad al haber afectado a los ecuatorianos y los relaciona con el status quo.

Para completar la extensión del mito de la Revolución Ciudadana y legitimar a su nosotros, en los componentes despliega un mayor relato sobre sus prodestinatarios y sus contradestinatarios. Dibuja a su gobierno como lleno de éxitos, reconocido en el mundo y ajeno al "pasado" negativo de crisis e inestabilidad que vivió Ecuador, al cual lo recuerda reiteradamente de esa forma. Sobre el presente, afirma que el gobierno de Moreno ha revivido a ese pasado negativo, coloca elementos emocionales - como el miedo- para rechazar el retorno de ese pasado que pondría en peligro a la patria. También se refiere al lawfare como estrategia de sus contradestinatarios (los medios, el gobierno de Moreno, grupos económicos y el sector justicia) cuyo objetivo sería perseguir a Correa y a su tendencia ideológica, situación que también ocurriría en varios países de la región.

La estrategia de Rafael Correa entonces así reitera en su discurso la lógica del antagonismo social para intentar recuperar la fortaleza de su nosotros y extender el mito de la Revolución Ciudadana.

Finalmente, esta investigación da paso a futuras investigaciones de discursos políticos en Ecuador debido a la renovación de escenarios, por ejemplo, a partir de las próximas elecciones presidenciales en el país en 2021 que podrían marcar una nueva formación de aliados y opositores. 


\section{REFERENCIAS BIBLIOGRÁFICAS}

Abad, G. (2010). El club de la pelea. Poder político vs. poder mediático. En O. Rincón (Ed.), ¿Por qué nos odian tanto? Estado y medios de comunicación en América Latina (pp. 183-198). Bogotá, Colombia: Centro de Competencia en Comunicación para América Latina Friedrich Ebert Stiftung.

Andino, B. (2020). El nosotros y los otros en los discursos del presidente ecuatoriano Lenín Moreno durante 2018. Comunicación y Medios, 41, 29-41. Recuperado de https://n9.cl/vp7tc

Andrade A., P. (2006). Democracia liberal e inestabilidad política en Ecuador. Apuntes para una interpretación política. OASIS, 11, 167-189. Recuperado de https://n9.cl/a7o4

Ávila Nieto, C. (2012). El mito como elemento estratégico de comunicación política: aplicación del modelo de Barthes al caso ecuatoriano. Cuadernos.info, 31, 139-150. Recuperado de https://n9.cl/34qf

Borja, R. (18 de julio de 2018). Enciclopedia de la Política. Recuperado de http://www.enciclopediadelapolitica.org/partidocracia/

Canal Uno. (enero de 2018). Entrevista a Rafael Correa por Rafael Cuesta. Recuperado de https://www.youtube.com/watch?v=ukZuHXNYGK4

Cerbino, M., Maluf, M. y Ramos, I. (2016). Los Enlaces Ciudadanos del presidente Rafael Correa: entre la exaltación del pueblo y el combate a los medios. Quito, Ecuador: FLACSO Ecuador.

CNN (diciembre de 2018). Entrevista a Rafael Correa. Recuperado de https://www.youtube.com/watch?v=Dbh30Eyxzyg

De la Torre, C. (2015). De Velasco a Correa. Insurrecciones, populismos y elecciones en Ecuador 1944-2013. Quito, Ecuador: Corporación Editora Nacional.

Ecuador TV. (enero de 2018). Entrevista a Rafael Correa en Palabra Suelta. Recuperado de https://www.youtube.com/watch?v=04zMGR92do8 
Enlace Digital. (octubre de 2018). Discurso de Rafael Correa. Recuperado de https://www.youtube.com/watch?v=1SvkzO-gcX8

HispanTV. (julio de 2018). Entrevista a Rafael Correa. Recuperado de https://www.youtube.com/watch?v=Mgs-mskJv0c

Laclau, E. (2005). La Razón populista. Buenos Aires, Argentina: Fondo de Cultura Económica.

Laclau, E.y Mouffe, C. (1987). Hegemonía y estrategia socialista. Hacia una radicalización de la democracia. Madrid, España: Siglo XXI.

Rancière, J. (1996). El desacuerdo. Política y filosofía. Buenos Aires, Argentina: Ediciones Nueva Visión SAIC.

Russia Today. (julio de 2018). Entrevista a Rafael Correa. Recuperado de https://www.youtube.com/watch?v=A1H1n9BjOJk

Stoessel, S. (2014). Las categorías de hegemonía, antagonismo y populismo en la teoría política contemporánea. Una aproximación desde la obra post-marxista de Ernesto Laclau. Utopía y Praxis latinoamericana, 64, 13-32. Recuperado de https://n9.cl/qebp2 Telesur. (febrero de 2018). Entrevista a Rafael Correa. Recuperado de https://www.youtube.com/watch?v=tXqVyjDjDBI

Van Dijk, T. A. (1999). El análisis crítico del discurso. Anthropos, 186, 23-36.

Verón, E. (1987). La palabra adversativa. Observaciones sobre la enunciación política. En E. Verón, El discurso político: Lenguajes y acontecimientos (pp. 11-26). Buenos Aires, Argentina: Hachette. 